\title{
The presence of A5935G, G5949A, G6081A, G6267A, T9540C mutations in MT-CO1 and MT-CO3 genes and other variants of MT-CO1 and MT-CO3 gene fragments in the study population diagnosed with endometrial cancer
}

\author{
Kinga Księżakowska-Łakoma ${ }^{1}$, Dominika Kulczycka-Wojdala ${ }^{2}$, \\ Andrzej Kulig ${ }^{3}$, Marcin Baum4, Jacek R. Wilczyński ${ }^{1,5}$ \\ 'Department of Gynecology, Chair of Obstetrics \& Gynecological Surgery, Medical University in Lodz, Poland \\ ${ }^{2}$ The Central Laboratory of Medical University in Lodz, Medical University of Lodz, Poland \\ ${ }^{3}$ Department of Pathomorphology, "Polish Mother's Memorial Hospital" Research Institute, Lodz, Poland \\ ${ }^{4}$ Department of Perinatology, "Polish Mother's Memorial Hospital" Research Institute, Lodz, Poland \\ ${ }^{5}$ Department of Gynecological Surgery and Gynecological Oncology, \\ "Polish Mother's Memorial Hospital" Research Institute, Lodz, Poland
}

\begin{abstract}
Objectives: The specific purpose of this study was the assessment of A5935G, G5949A, G6081A, G6267A mutations in MT-CO1 and T9540C in MT-CO3, and alterations detected during the analysis of MT-CO gene fragments in subject and control groups. A secondary aim was to assess the relationship between MT-CO1 and MT-CO3 gene alterations and endometrial cancer incidence and evaluation of the prognostic value of MT-CO1 and MT-CO3 gene alterations.

Material and methods: In this study, we investigated A5935G, G5949A, G6081A, G6267A mutations in MT-CO1 and T9540C in MT-CO3, and alterations detected during the analysis of MT-CO gene fragments in formalin-fixed, paraffin-embedded endometrial and benign endometrial hyperplasia of a cohort of 125 subjects.

Results: The T9540C mutation in MT-CO3 was detected in one patient from the subject group. None of the remaining mutations were detected. The research showed that the presence of alterations in MT-CO1 and MT-CO3 typical of other types of cancer is not a risk factor for endometrial cancer.

Analysis of MT-CO1 and MT-CO3 gene fragments revealed 10 alterations ( 6 and 4 respectively). The alterations detected were identified in $10 \%$ of the tested group and $8 \%$ of the control group.

Conclusions: The research showed that the presence of alterations in MT-CO1 (A5935G, G5949A, G6081A, G6267A) typical of other types of cancer is not a risk factor for endometrial cancer. Three new alterations detected in this study (A6052G, A9545G, G9575A) were described for the first time.
\end{abstract}

Key words: mtDNA mutations, alterations in MT-CO1, alterations in MT-CO3, endometrial cancer

Ginekologia Polska 2017; 88, 7: 343-348

\section{INTRODUCTION}

In recent years, there has been a rise in the number of reported mtDNA mutations predisposing to neoplasm growth. There are few studies concerning MT-CO genes mutations on endometrial cancer development. Thus, the present study is an attempt to complete the knowledge concerning the meaning of mtDNA disorders in endometrial cancer development. 
We would like to focus on A5935G, G5949A, G6081A, G6267A mutations in MT-CO1 and T9540C in MT-CO3 presence and other variants of MT-CO1 and MT-CO3 gene fragments in the study population. The mutations selected for this research occur in prostate, breast, pancreatic cancer, colorectal cancer as well as ulcerative colitis [1, 2].

Alterations of MT-CO can lead to dysfunction of mitochondrial respiratory chain complex IV, which leads to changes in cellular metabolism, resulting in modifications to the cell's susceptibility to cancerous transformation [3-5].

A5935G, G5949A, G6081A, G6267A are nonsynonymous mutations which stem from transition ( $A-G$ or $G-A$ ) and change the amino acid in protein product of MT-CO1.

The A5935G mutation exchanges asparagine for serine at position 11 in cytochrome c oxidase's first subunit, resulting in protein function impairment. Substitution of an asparagine radical for a serine radical prevents the formation of multiple hydric bonds, which may disrupt protein tertiary structure. In addition, the alteration can destabilize transmembrane protein (conduit D) structure, which serves as a pathway for proton transfer in oxygen reduction $[1,6,7]$.

Another G5949A mutation, detected in prostate cancer, triggers premature formation of STOP codon in MT-CO1, which results in a shorter polypeptide length of 15 amino acids, instead of 513 amino acids. The shorter polypeptide product is highly unstable and quickly breaks down. In effect, this mutation decreases COX1 and COX2 levels. The unstable protein structure and its decreased concentration impairs the assembly process of oxidative phosphorylation IV subunit $[1,7,8]$.

The G6081A mutation introduces alanine radical instead of threonine into the $60^{\text {th }}$ position on cytochrome c oxidase. In most Eukaryotes, $60^{\text {th }}$ position of polypeptide contains amino acids with a small molecular weight such as alanine or glycine. A replacement of alanine with threonine with its branched lateral chain in the $60^{\text {th }}$ position and close proximity to heme group iron stabilizer histidine can disrupt protein helix structure. Polypeptide secondary structure dysfunction can affect electron transfer via a heme $[7,9,10]$.

The $6267 \mathrm{G}>$ A change prompts the replacement of alanine radical with threonine at $122^{\text {th }}$ locus of the polypeptide. Similarly to A5935G and G6081A mutations, alanine radical in this locus is highly evolutionarily preserved. According to the authors, cells with G6267A mutation have restricted growth on culture medium without glucose. It can suggest respiratory chain failure due to this mutation $[2,7]$.

The T9540C mutation is a $\mathrm{T}=>\mathrm{C}$ transition, characteristic of oxidative stress damage [11]. This mutation causes a change in mRNA codon from UUA to CUA, which does not, however, lead to a change of amino acids in the protein chain. It is therefore a silent mutation [12].

\section{MATERIAL AND METHODS}

Material for the trial included:

- formalin-fixed, paraffin-embedded (FFPE) endometrial cancer (adenocarcinoma endometrioides) samples collected during abdominal hysterectomy and stored at Clinical Pathomorphology Department in "Polish Mother's Memorial Hospital" Research Institute in Lodz. Tested samples were taken from 100 European women operated on for endometrial cancer of varying stages according to the FIGO cancer staging system and malignancy grading in the Department of Gynecology ICZMP in Lodz from 2007 to 2014 (subject group);

- formalin-fixed, paraffin-embedded (FFPE) histopathological specimens of benign endometrial hyperplasia stored at Clinical Pathomorphology Department. The samples were collected from 25 patients diagnosed with abnormal vaginal bleeding who underwent dilation and curettage (D \& C) at the Department of Gynecology from 2011 to 2012 (control group).

\section{Ethical aspect}

The study was approved by the local ethic committee of "Polish Mother's Memorial Hospital” Research Institute (ethical agreement 3/2011).

\section{DNA isolation}

Genomic and mitochondrial DNA were extracted from formalin-fixed, paraffin-embedded (FFPE) endometrial cancer and benign endometrial hyperplasia samples by using the QIAamp DNA FFPE Tissue Kit (Qiagen, Germany) in accordance with the manufacturer's protocol (purified DNA is free of proteins, nucleases, and other impurities).

The concentration (A260) and purity (A260/A280 ratio) of isolated DNA were determined by using a PicoDrop — spectrophotometer (Picodrop Limited, United Kingdom). The extracted pure DNA was used in amplification reactions or stored at $-20^{\circ} \mathrm{C}$.

\section{Polymerase chain reaction amplification}

The purified DNA was used as a template for PCR amplification. The reaction mixture in $20 \mu \mathrm{L}$ volume contained $50 \mathrm{ng}$ of DNA, 1 UTaq DNA polymerase (Promega, USA), $1.5 \mathrm{mM} \mathrm{MgCl}_{2}, 0.25 \mathrm{mM}$ each of dATP, dCTP, dGTP, and dTTP, and $0.5 \mu \mathrm{M}$ of the primers.

Amplification was performed with a thermal cycler, GeneAmp PCR System 9700 (Applied Biosystems, USA).

The following $C O X 1$ and $C O X 3$ - specific sets of primers were used:

\section{cOX1}

For: 5 '-GAAAATCACCTCGGAGCTGG-3'

Rev: 5'-GATGGTTAGGTCTACGGAGG-3 


\section{COX3}

For: 5'-GGCCTTCGATACGGGATAAT-3'

Rev: 5'-ATGGTGAGCTCAGGTGATTG-3'

Thermal cycling conditions for PCR reactions included an initial denaturation step at $95^{\circ} \mathrm{C}$ for 5 minutes followed by 30 cycles of a denaturation step at $95^{\circ} \mathrm{C}$ for 30 seconds, a primer annealing step at $60^{\circ} \mathrm{C}$ for 30 seconds, an extension step at $72^{\circ} \mathrm{C}$ for 30 seconds, and a final step at $72^{\circ} \mathrm{C}$ for 7 minutes.

\section{Microchip electrophoresis of DNA fragments}

The PCR amplification products were separated and analyzed on the automated microchip electrophoresis system MCE-202 MultiNa (Shimadzu, Japan) using the DNA-1000 kit according to the manufacturer's protocol. A SYBR Gold fluorescent dye for DNA staining (Invitrogen, USA) and PhiX174 DNA/Hae III Markers (Promega, USA) were used to determine the size of the PCR products.

\section{Sequencing}

Amplification products were purified using MiniElute PCR Purification Kit (Qiagen, Germany). The sequencing reactions were run using a Big Dye ${ }^{\circledR}$ Terminator v1.1 Cycle Sequencing Kit (Applied Biosystems, USA) on the GeneAmp PCR System 9700 using standard sequencing protocols. Sequence analysis was performed by using the same primers as previously used in preamplification step.

The PCR products were purified to eliminate unincorporated primers and dNTPs using BigDye XTerminator Purification Kit and then subjected to separation by the 3130xl GeneGenetic Analyzer (Applied Biosystems).

The DNA sequences were analyzed using DNA Baser Sequence Assembler.

\section{Statistical analysis}

STATISTICA 10.0 (StatSoft, Inc., USA) and Excel MS Office 2013 (Microsoft Corporation, USA) software was used in the course of the research to process and analyze the data.

\section{RESULTS}

The T9540C mutation in MT-CO3 was detected in one patient from the subject group.

None of the remaining mutations (A5935G, G5949A, G6081A, G6267A into MT-CO1) were detected in either patient group.

Analysis of MT-CO1 and MT-CO3 gene fragments revealed 8 alterations ( 5 and 3 respectively). The alterations detected in $9 \%$ of the study group and $8 \%$ of the control group. The most common alterations included: A6047G with an incidence of $2 / 100(2 \%)$ in the study group and $1 / 25$ (4\%) in the control group and T5999C with an incidence

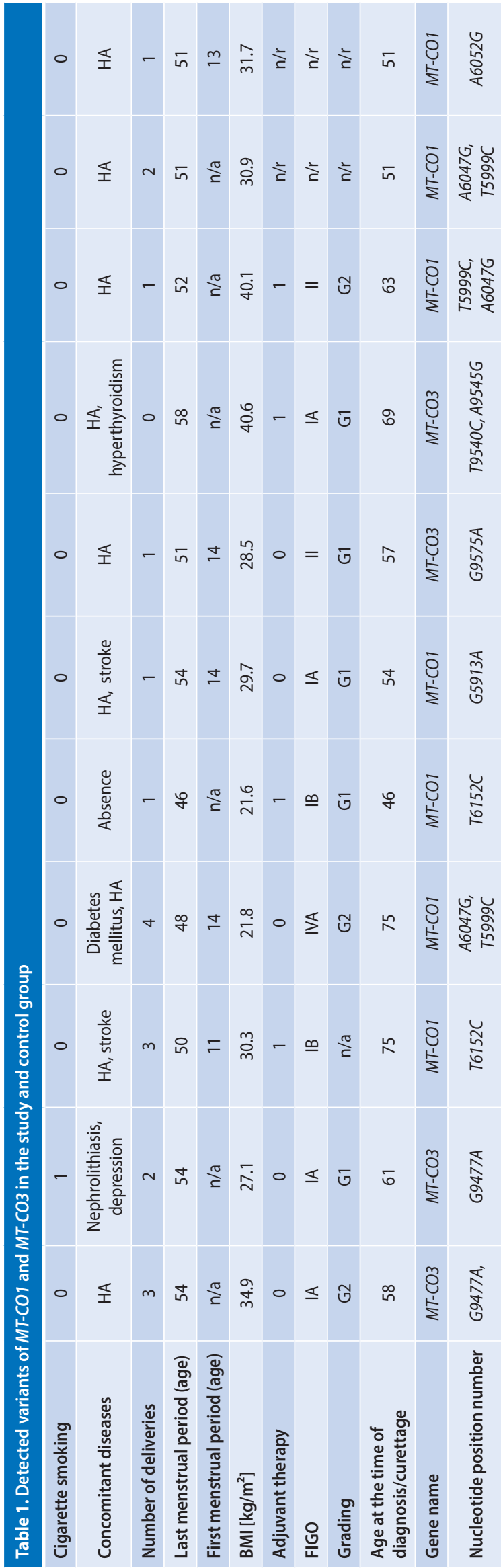


of $2 / 100$ (2\%) in the study group and $1 / 25$ (4\%). T6152C, G9477A mutations were also detected in the study group, each with an incidence of 2/100 (2\%).

The remaining variants G5913A, G9575A, A9545G occurred in $1 \%(1 / 100)$ of the study group while $A 6052 \mathrm{G}$ was found in $4 \%(1 / 25)$ of the control group.

As the above data demonstrates, only 2 MT-CO gene variants were detected in both the study and control group. Given their low incidence testing for these mutations seems to be unwarranted.

In the study group MT-CO1 and MT-CO3 gene variants were detected, whereas in the control group only alterations in MT-CO1 were observed.

Table 1 shows a summary of MT-CO1 and MT-CO3 genes mutations including medical history data from patients in the study and control groups.

Due to the rarity of the aforesaid alterations statistical analysis could not be performed as it would be unreliable.

Among the detected mutations are those observed in prostate cancer, pancreatic cancer, glioblastoma multiforme, hydatidiform mole, ovarian and thyroid cancers, head and neck cancers (Table 2). The remaining 3 alterations were described for the first time in this study (Table 3 ).

Three of the detected variants are transitions (A-G or $\mathrm{G}-\mathrm{A}$ ) leading to amino acid change in the protein product of MT-CO1 and MT-CO3. The effect of the amino acid change on polypeptide structure and function was analyzed based on UniProt database [19].

The G5913A mutation substitutes asparagine radical for aspartate into the $4^{\text {th }}$ locus of COX 1 subunit. Amino acids presented in the $4^{\text {th }}$ locus are different for Eukaryote species. As the data in the chart implies, the sequence containing the mutation is not evolutionarily preserved. Therefore it seems safe to assume that the amino acid change does not affect polypeptide properties.

The A6052G mutation, which causes substitution of asparagine with serine in the $50^{\text {th }}$ locus of cytochrome $c$ oxidase's first subunit, is highly evolutionarily modified. Poor evolutionary variability of a given sequence may suggest that amino acid substitution does not alter protein structure or function.

Also the G9477A mutation causing the substitution of valine with isoleucine at locus 91 does not change the phenotype. One of the human variants of polypeptide first subunit of cytochrome c oxidase is the occurence of isoleucine at locus 91 . Isoleucine located at locus 91 occurs in $17.5 \%$ of the European and $6.7 \%$ of the African population [19]. The remaining MT-CO1 and MT-CO3 gene variants detected in this study do not cause any amino acid change.

Table 2. Detected variants in MT-CO1 and MT-CO3 in study population observed in other neoplasms

\begin{tabular}{|c|c|c|c|c|c|}
\hline References & {$[13,14]$} & [15] & {$[13,14]$} & {$[1,16]$} & {$[17,18]$} \\
\hline Type of cancer & $\begin{array}{c}\text { Glioblastoma } \\
\text { multiforme, } \\
\text { pancreatic cancer }\end{array}$ & $\begin{array}{l}\text { Head and neck } \\
\text { squamous cell } \\
\text { carcinoma }\end{array}$ & $\begin{array}{c}\text { Glioblastoma } \\
\text { multiforme, } \\
\text { pancreatic cancer }\end{array}$ & $\begin{array}{l}\text { Prostate cancer, } \\
\text { hydatidiform mole }\end{array}$ & $\begin{array}{l}\text { Thyroid and } \\
\text { ovarian cancers }\end{array}$ \\
\hline Amino acid change & Leu 48 Leu & Val 83 Val & Ala 32 Ala & Asp 4 Asn & Val 91 lle \\
\hline $\begin{array}{l}\text { Altered codon sense } \\
\text { mtDNA strand }\end{array}$ & CTG & GTC & GCC & AAC & ATT \\
\hline $\begin{array}{l}\text { Codon sense } \\
\text { mtDNA strand }\end{array}$ & CTA & GTT & GCT & GAC & GTT \\
\hline Gene name & MT-CO1 & MT-CO1 & MT-CO1 & MT-CO1 & MT-CO3 \\
\hline Substitution & $A-G$ & $\mathrm{~T}-\mathrm{C}$ & $\mathrm{T}-\mathrm{C}$ & G-A & G-A \\
\hline $\begin{array}{l}\text { Nucleotide position } \\
\text { number }\end{array}$ & 6047 & 6152 & 5999 & 5913 & 9477 \\
\hline
\end{tabular}

A - adenine, C - cytosine, G - guanine, T — thymine, Leu — leucine, Val — valine, Ala — alanine, Asp — asparagine, Asn — aspartate, Ile — isoleucine

Table 3. Variants of MT-CO1 and MT- $\mathrm{CO} 3$ identified in the study population but absent from the available literature

\begin{tabular}{|l|c|c|c|c|c|}
\hline Nucleotide position number & Substitution & Gene name & $\begin{array}{c}\text { Codon sense } \\
\text { mtDNA strand }\end{array}$ & $\begin{array}{c}\text { Modified codon sense } \\
\text { mtDNA strand }\end{array}$ \\
\hline 6052 & Amino acid change \\
\hline 9545 & A-G & MT-CO1 & MT-CO3 & AAC & AGC \\
\hline 9575 & G-A & MT-CO3 Ser & GCG & Gly 113 Gly \\
\hline
\end{tabular}

Leu — leucine, Asn — aspartate, Gly — glycine, Pro — prolin 


\section{DISCUSSION}

In recent years, there has been a rise in the number of reported congenital and somatic mutations as well as mtDNA polymorphisms predisposing to neoplasm growth. Among the mutations tested in the subject population the T9540C mutation in MT-CO3 was detected in one of the patients diagnosed with endometrial cancer. Due to the mutation's sporadic occurrence, $1 / 100$ patients, the case is statistically irrelevant and does not qualify for further statistical analysis.

The T9540C reported in breast cancer is a germline mutation, i.e. one present in both cancerous and healthy cells of the same individual. Germline mutations are transmitted from one generation to the next [20]. Likewise, in case of ovarian cancer, investigators determined the T9540C variant to be a germline mutation based on tumor and healthy cell samples taken from sons of mothers diagnosed with ovarian cancer [21]. The T9540C mutation also occurs in ulcerative colitis, chronic inflammatory disease predisposing to colorectal cancer [22].

Analysis of $M T-C O 1$ and $M T-C O 3$ gene fragments for other changes revealed: variants in MT-CO1 (A6047G, T6152C, T5999C, G5913A, A6052G) and in MT-CO3 (G9477A, A9545G, G9575A).

Among the detected mutations are those observed in other neoplasms: prostate cancer and hydatidiform mole (G5913A) [1, 16], pancreatic tumor and glioblastoma multiforme (A6047G, T5999C) [13, 14], ovarian and thyroid cancers (G9477A) [17, 18], head and neck squamous cell carcinoma (T6152C) [15]. The remaining 3 alterations (A6052G, A9545G, G9575A) were described in this study for the first time.

The G5913A mutation desribed by Petros at al. [1] is a transition $(G>A)$ which causes substitution of aspartate with asparagine at $4^{\text {th }}$ locus of COX 1 product. The locus where amino acid substitution occurred is highly evolutionarily modified. It is therefore improbable that the changed amino acid affects the polypeptide's phenotype [1, 7]. The same mutation occurs in hydatidiform mole, a disease which predisposes to choriocarcinoma [16].

Researchers have suggested a relationship between A6047G and T5999C mutations occuring in glioblastoma multiforme and oxidative stress in cancerous cells. They suspect there is a correlation between the transition and both respiratory chain failure and an increased concentration of reactive oxygen species [13, 23-26]. Investigators of mtDNA variants in pancreatic cancer have inferred a similar conclusion [14].

In the course of study on somatic mutations in human thyroid cancer, where 68 patients were enrolled, MT-CO1 and $M T-C O 3$ gene mutations were detected in 9 patients. The G9477A mutation occured in tumoral and adjacent healthy tissue samples from 3 patients. Scientists demonstrated a prevalence of variants of genes encoding complex IV in malignant tumors compared with benign neoplasms [17]. The G9477A mutation, also described in ovarian cancer, increases the risk of its incidence by 1.27 times [18]. Another T6152C mutation was first described in head and neck squamous cell carcinomas. Researchers focused mainly on the analysis of D-loop vatiants, but did not imply any statistically significant relationship between detected alterations and head and neck cancers as the tested variants were too rare [15].

The variants of MT-CO1 and MT-CO3 described in this study for the first time are also transitions. One of them, namely A6052G, introduces serine instead of asparagine into the $50^{\text {th }}$ locus of $C O X 1$ subunit. The sequence where the amino acid change occurred is not evolutionarily preserved. Given the low evolutionary diversity of the studied sequence it seems safe to assume that amino acid substitution does not affect polypeptide structure or function [19]. The two remaining variants detected in this study do not trigger any amino acid change in the protein product.

Due to the limited reports on MT-CO1 and MT-CO3 gene mutations in endometrial cancer, selected mutations and variants detected in endometrial cancer patients and the study group during MT-CO gene fragments testing were subject to further analysis.

It was a rather difficult task since compared with the variants in hypervariable D-loop region these mutations occur only in a small portion of the studied neoplasms. Petros et al. [1] studied mutations in MT-CO1 occuring in only $11-12 \%$ of the population with prostate cancer and in $<2 \%$ of the control group. Among the 17 patients diagnosed with glioblastoma multiforme only one carried an MT-CO1 gene mutation, the remaining alterations were mostly located in D-loop [13]. Similarly, out of 68 thyroid cancer patients MT-CO1 and MT-CO3 gene mutations were detected in 9 cases [17]. Nevertheless, the influence of mtDNA mutations encoding respiratory chain subunits impairs energy and metabolic processes in cells, and affects the function of tissues and thus the whole body. The importance of this question prompted us to study MT-CO1 and MT-CO3 gene mutations in endometrial cancer.

\section{CONCLUSIONS}

The analysis performed indicates none of the remaining MT-CO1 mutations (A5935G, G5949A, G6081A, G6267A) occur in endometrial cancer.

Three new alterations detected in this study (A6052G, A9545G, G9575A) were described for the first time.

\section{Authors' contribution}

Kinga Księżakowska-Łakoma - concept and design of stu$\mathrm{dy}$, collection of material, analysis and interpretation of data; Dominika Kulczycka-Wojdala — performing laboratory 
analysis of research material; Andrzej Kulig - collection of histopathological specimens; Marcin Baum - collection of material; Jacek R. Wilczyński - analysis and interpretation of data, final version and acceptance of the manuscript.

\section{Source of financing}

Research grant of Medical University in Lodz No. 502-03/ /5/105-02/502-54-113.

\section{Conflict of interest}

This publication is approved by all authors. The authors declare no commercial or financial conflict of interest. The article has not been published and it is not being considered for publication elsewhere.

\section{REFERENCES}

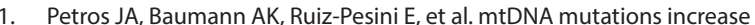
tumorigenicity in prostate cancer. Proc Natl Acad Sci U S A. 2005; 102(3): 719-724, doi: 10.1073/pnas.0408894102, indexed in Pubmed: 15647368.

2. Gallardo ME, Moreno-Loshuertos R, López C, et al. m.6267G>A: a recurrent mutation in the human mitochondrial DNA that reduces cytochrome $\mathrm{c}$ oxidase activity and is associated with tumors. Hum Mutat. 2006; 27(6): 575-582, doi: 10.1002/humu.20338, indexed in Pubmed: 16671096.

3. Czarnecka AM, Golik P, Bartnik E. Mitochondrial DNA mutations in human neoplasia.J Appl Genet. 2006;47(1):67-78, doi: 10.1007/BF03194602, indexed in Pubmed: 16424612

4. Brandon $M$, Baldi $P$, Wallace DC. Mitochondrial mutations in cancer. Oncogene. 2006; 25(34): 4647-4662, doi: 10.1038/sj.onc.1209607, indexed in Pubmed: 16892079.

5. Czarnecka A, Bartnik E. Mitochondrial DNA mutations in tumors. Cellular Respiration and Carcinogenesis. 2008: 119-130, doi: 10.1007/978-159745-435-3 9.

6. Papa S, Capitanio N, Capitanio G, et al. Protonmotive cooperativity in cytochrome c oxidase. Biochim Biophys Acta. 2004; 1658(1-2): 95-105, doi: 10.1016/j.bbabio.2004.04.014, indexed in Pubmed: 15282180.

7. Plak K, Kukwa W, Bartnik E, et al. Występowanie mutacji w mtDNA i ich potencjalny wpływ na strukturę białek w wybranych typach nowotworów. Postępy Biochemii. 2008; 54: 151-160.

8. D'Aurelio $M$, Pallotti $F$, Barrientos $A$, et al. In vivo regulation of oxidative phosphorylation in cells harboring a stop-codon mutation in mitochondrial DNA-encoded cytochrome c oxidase subunit I. J Biol Chem. 2001; 276(50): 46925-46932, doi:10.1074/jbc.M106429200, indexed in Pubmed: 11595737.

9. Betts MJ, Russell BR. Amino acid properties and consequences of substitutions. In: Barnes MR. ed. Bioinformatics for Geneticists. Second edition. John Wiley \& Sons, Ltd 2007: 311-342.

10. Tsukihara T, Aoyama H, Yamashita E, et al. The whole structure of the 13-subunit oxidized cytochrome c oxidase at 2.8 A. Science. 1996; 272(5265): 1136-1144, indexed in Pubmed: 8638158.
11. Liu VWS, Yang HJ, Wang $Y$, et al. High frequency of mitochondrial genome instability in human endometrial carcinomas. Br J Cancer. 2003; 89(4): 697-701, doi: 10.1038/sj.bjc.6601110, indexed in Pubmed: 12915881.

12. Ferenc T, Olszewska-Słonina D, Bratkowska W. Ekspresja genów. In: Drewa G, Ferenc T. ed. Podstawy genetyki dla studentów i lekarzy. Wydanie II poprawione i uzupełnione. Wydawnictwo Medyczne Urban \& Partner, Wrocław 2003: 55-90.

13. Kirches $E$, Krause $G$, Warich-Kirches $M$, et al. High frequency of mitochondrial DNA mutations in glioblastoma multiforme identified by direct sequence comparison to blood samples. Int J Cancer. 2001; 93(4): 534-538, indexed in Pubmed: 11477557.

14. Jones JB, Song JJ, Hempen PM, et al. Detection of mitochondrial DNA mutations in pancreatic cancer offers a "mass"-ive advantage over detection of nuclear DNA mutations. Cancer Res. 2001; 61(4): 1299-1304, indexed in Pubmed: 11245424.

15. Challen $\mathrm{C}$, Brown $\mathrm{H}_{\text {, Cai }} \mathrm{C}$, et al. Mitochondrial DNA mutations in head and neck cancer are infrequent and lack prognostic utility. $\mathrm{Br} J$ Cancer. 2011; 104(8): 1319-1324, doi: 10.1038/bjc.2011.96, indexed in Pubmed: 21427725.

16. Chiu PM, Liu VWS, Ngan HYS, et al. Detection of mitochondrial DNA mutations in gestational trophoblastic disease. Hum Mutat. 2003; 22(2): 177, doi: 10.1002/humu.9160, indexed in Pubmed: 12872261.

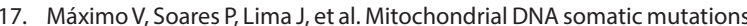
(point mutations and large deletions) and mitochondrial DNA variants in human thyroid pathology: a study with emphasis on Hürthle cell tumors. Am J Pathol. 2002; 160(5): 1857-1865, doi: 10.1016/S00029440(10)61132-7, indexed in Pubmed: 12000737.

18. Earp MA, Brooks-Wilson A, Cook L, et al. Inherited common variants in mitochondrial DNA and invasive serous epithelial ovarian cancer risk. BMC Res Notes. 2013; 6: 425, doi: 10.1186/1756-0500-6-425, indexed in Pubmed: 24148579.

19. Data were designed from Uni Prot database [online], http://www. uniprot.org/ [access: 1.02.2015].

20. Tan DJ, Bai RK, Wong LJC. Comprehensive scanning of somatic mitochondrial DNA mutations in breast cancer. Cancer Res. 2002; 62(4): 972-976, indexed in Pubmed: 11861366.

21. Wani AA, Sharma N, Shouche YS, et al. Nuclear-mitochondrial genomic profiling reveals a pattern of evolution in epithelial ovarian tumor stem cells. Oncogene. 2006; 25(47): 6336-6344, doi: 10.1038/sj.onc.1209649, indexed in Pubmed: 16732329.

22. Nishikawa M, Oshitani N, Matsumoto T, et al. Accumulation of mitochondrial DNA mutation with colorectal carcinogenesis in ulcerative colitis. Br J Cancer. 2005; 93(3): 331-337, doi: 10.1038/sj.bjc.6602664, indexed in Pubmed: 15956973.

23. Beckman KB, Ames BN. Detection and quantification of oxidative adducts of mitochondrial DNA. Methods Enzymol. 1996; 264: 442-453, indexed in Pubmed: 8965717.

24. Beckman KB, Ames BN. Oxidative decay of DNA. J Biol Chem. 1997; 272(32): 19633-19636, indexed in Pubmed: 9289489.

25. Khrapko K, Coller HA, André PC, et al. Mitochondrial mutational spectra in human cells and tissues. Proc Natl Acad Sci U S A. 1997; 94(25): 13798-13803, indexed in Pubmed: 9391107.

26. Cadet J, Berger M, Douki T, et al. Oxidative damage to DNA: formation, measurement, and biological significance. Rev Physiol Biochem Pharmacol. 1997; 131: 1-87, indexed in Pubmed: 9204689. 